\title{
Produção de texto legível para a Intemet
}

\author{
Regina Rossetti ${ }^{1}$ \\ Clóvis Furla netto 2
}

\section{Resumo}

Este artigo visa levar ao conhecimento públic o como a legibilidade constitui uma importante ferramenta para a compreensão de conteúdo na Intemet. O legível é uma parte importante da construção textual e os atuais veículos de comunic ação necessitam a dequar sua produção para os novos tipos de leitores, sejam eles de blogs, vlogs, redes sociais digitais, entre outros. A concepção de texto que existia não se aplica ao atual panorama tecnológico existente. Os textos impressos estão gradativamente sofrend o uma mutação, ou seja, passando do estado estátic o para o modo dinâmico possibilitando uma interação entre o leitor e o meio de comunicação jamais vista antes. E sem a promoção de uma leitura clara e objetiva não poderá ocorrer a imersão do intemauta no universo das cores, imagens, vídeos e palavras. O trabalho explora as possibilidades que poderão permitir o a cesso a um novo nível de leitura de conteúdo.

Palavras chave: legibilidade; cores; digital.

\section{Abstract}

This article aims to bring to public attention as legibility is an important tool for understanding content on the Intemet. The readable is an important part of the textual construction and the current means of communic ation need to adapt their production to the new types of readers, be they blogs, vlogs, digital social networking, among others. The design of text that did not exist applies to the pela USP com pós-doutoramento pela mesma Instituição. .

2 Mestre em Comunicação pela Universidade de São Caetano do Sul. Professor no curso de J omalismo da Universidade São Judas Ta deu.

Revista Pauta Geral-Estudos em J omalismo, Ponta Grossa, vol.3, n.1 p. 41-56, J an/J un, 2016. 
current existing technological landscape. Printed texts a re gradually undergoing a mutation, ie, moving from static state to dynamic mode enabling an interaction between the reader and the medium has ever seen before. And without promoting a clear and objective reading can notoccur the Intemet user's immersion in the world of colors, images, videos and words. The work explore the possibilities that may allow access to a new level of reading content.

Keywords: readability; color; digital.

\section{Leitura e a veiculação da notícia}

A leitura textual na internet não deve ser considerada como a tradicional em papel, pois para que sua legibilidade seja plena há elementos que devem ser levados em consideração na concepção do conteúdo a ser veiculado na internet. Com a chegada da Internet no Brasil em 1995, os veículos de mídia tradicionais vislumbraram um novo nicho para seus conteúdos e segundo Pinho (2003, p.181) "a história é antiga e se repete por ocasião do nascimento de cada nova mídia. O rádio, o cinema e a televisão, cada um no seu tempo, surgiram com conteúdos que reproduziam as mídias que os precederam". Neste caso a mídia online agregou em seu estilo os conceitos de veículos tradicionais: o texto do impresso, o áudio e vídeo da televisão e a agilidade do rádio.

Este foi um primeiro passo para que outros elementos pudessem ser inseridos. Neste aspecto será demonstrado como os conceitos de diagramação foram atualizados para poderem ser melhorados e adequados aos veículos digitais modernos. Neste quesito é importante começar pela tipologia mais adequada, ou seja, o tipo de letra que devemos utilizar para escrever o conteúdo - na realidade não há um padrão adotado pelos portais de notícias, mas uma culturalização de hábitos.

Warde (2006,p.126) afirma que o meio online é também, principalmente, um ambiente na tela. Existem telas em todos os formatos, tamanhos e posições, porém elas ainda possuem resolução inferior à alta qualidade da página impressa. Ler na tela pode ser uma tarefa difícil. A afirmação vai de encontro com o que encontramos na leitura da atualidade seja em telas de computadores ou celulares, a principal preocupação é adequar os textos para os diversos monitores. Em maior ou menor grau de conteúdo, enquanto em materiais impressos podemos realizar uma leitura direta sem paradas, na tela do computador somos obrigados a parar a sequência de decodificação do texto para "rolar" a tela ou ainda somos distraídos por algum tipo de publicidade que surge de Revista Pauta Geral-Estudos em J omalismo, Ponta Grossa, vol.3, n.1 p. 41-56, J an/J un, 2016. 
repente no texto. Então a questão do design gráfico e seus elementos que são essenciais a toda boa diagramação na WEB necessitam ser adequados aos atuais sistemas para atender às necessidades dos leitores online, pois caso contrário as redes sociais não seriam atrativas o suficiente para agradar aos visitantes dos jornais digitais.

Um exemplo de má utilização de elementos do design é o espaço em branco, que segundo J. B. Pinho:

é, por definição, determinada área em uma peça impressa - como cartazes, anúncios, folhetos - que não tenha texto, imagens ou outro elemento de design. Os espaços em branco não são áreas perdidas ou desperdiçadas, garante Radfather (1999, p.46) porque 'funcionam para equilibrar espaços, reforçar a unidade de grupos e aumentar o contraste. (...)"(PINHO, 2003, p.192).

A imagem, a seguir, do site www.yahoo.com.br exemplifica a má utilização do espaço para o conteúdo. Ao terminar o texto há um "buraco" - espaço em branco que não foi utilizado adequadamente causando um ruído visual na leitura do material publicado.

Figura 1: Imagem ilustrativa de exemplo da má utilização do espaço para publicação de conteúdo

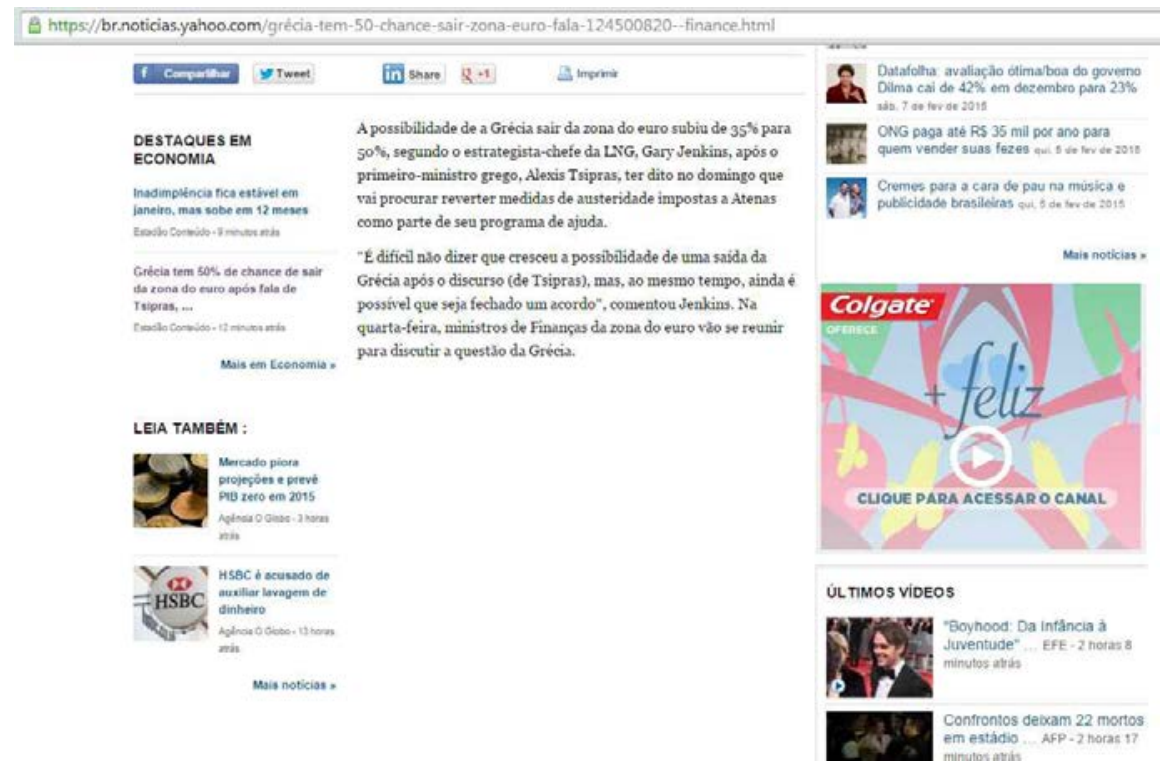

Fonte: Site de Notícias www.yahoo.com.br (https://br.noticias.yahoo.com/gr\%C3\%A9cia-tem50-chance-sair-zona-euro-fala-124500820--finance.html) - 09/02/2015

Revista Pauta Geral-Estudos em J omalismo, Ponta Grossa, vol.3, n.1 p. 41-56, J an/J un, 2016. 
Um assunto que deve ser tratado com cuidado também é a questão da legibilidade textual em meios mediados por computadores, pois não estamos mais em uma plataforma estática e dimensionalmente unilateral como a folha impressa de um jornal diário, mas com as novas tecnologias disponíveis, a leitura de textos é feita em diversos modelos de telas que não se restringem mais a dos computadores de mesa. Os notebooks, ultrabooks, tablets e smartphones possuem tamanhos que variam de acordo com a necessidade do usuário e neste contexto a tipologia a ser utilizada pode ser determinante para a permanência e leitura de um texto por um usuário ou sua migração para outro site de conteúdo. Para um entendimento mais claro dos termos, a tipologia é o estudo dos tipos gráficos que utilizamos em uma produção impressa ou digital, isso vem de uma época em que a produção gráfica era realizada por equipamentos que possuíam letras (tipos) móveis que eram adequadas e formavam as palavras para a impressão. Na atualidade, em nosso mundo digital e dominado pelos computadores, os tipos receberam o nome de fontes e estas representam as variações que uma letra pode assumir, ou seja, temos uma vasta gama de formas de letras que são chamadas de famílias e englobam os mais diferentes modelos.

Levando-se em conta as diferentes mídias há uma diferença de qual tipo de fonte deve ser utilizada para melhorar a legibilidade.

No formato impresso optou-se pela fonte Times New Roman, pois esta utiliza um conceito que é conhecido por serifa, ou seja, possuem pequenas pontas ou hastes no começo e final de cada letra o que dá a sensação de continuidade de escrita. Este tipo de formato funciona no papel, pois a leitura é mais focada e estática. No caso das mídias online a leitura depende de fatores como a tela do computador (tamanho, luminosidade), o posicionamento do leitor em relação ao monitor e a necessidade de rolar o texto na tela. Por este motivo uma fonte mais limpa e sem serifa é indicada, pois possibilitará uma leitura mais contínua e sem quebras na sequência lógica do texto. Claro que o tamanho é de suma importância, pois o corpo da letra influenciará na maneira que o conteúdo será lido. Abro aqui um pequeno parêntese para explicar uma questão um pouco mais técnica sobre a utilização de fontes para os veículos online pelos diagramadores WEB. Os computadores atuais, bem como tablets, smartphones ou outra plataforma de acesso à internet são máquinas e como todo equipamento apenas obedece a comandos. Assim Revista Pauta Geral-Estudos em J omalismo, Ponta Grossa, vol.3, n.1 p. 41-56, J an/J un, 2016. 
sendo na hora que um conteúdo é publicado devemos optar por uma das famílias de fontes mais comuns aos hardwares existentes, ou seja, na hora em que um computador é adquirido ele já vem com uma coleção de fontes pré-instaladas e normalmente as fontes padrões são Times e Arial. Como foi dito anteriormente as letras não serifadas são as melhores na hora de uma leitura mais profunda utilizando um monitor então a Arial serve perfeitamente para a publicação dos textos na WEB e não causará nenhum tipo de conflito. Caso seja inserido o texto com uma fonte diferente da que o leitor possui em seu computador ocorrerá a desconfiguração de toda diagramação realizada no site.

Geralmente, na impressão, usamos um tipo de letra serifada para texto estendido; na tela, porém, a letra sem serifa pode ser mais fácil de ler. Escolher fonte para texto longo será uma preocupação se você estiver forçando um tipo de letra para sobrepor ao padrão do browser, ou se estiver criando parágrafos de texto como gráficos em um programa como photoshop. Caso contrário, deixe o visitante ajustar o próprio padrão - eles escolherão o tipo com o qual sentem-se mais confortáveis. (Williams e Tollet, p.216, 2001).

\section{A influência da cor na legibilidade}

Outro elemento essencial é a cor, pois a Internet é uma tela em branco de uma pintura que vai ganhando vida à medida que o artista - que neste caso podemos citar como sendo os desenvolvedores, webdesigners, jornalistas, publicitários, educadores, ou seja, todo aquele que de alguma maneira - contribui para a criação do espaço virtual e coloca um pouco de sua experiência na concepção de um site, blog ou outro ambiente, onde as pessoas interagem em busca de conhecimento, entretenimento, diversão ou qualquer tema que Ihe interesse. No início dos anos 1990 não haviam computadores como os atuais e só existia uma cor: as telas verdes dos antigos 386 ou 486 e lá pela metade desta década os monitores preto e branco surgiam para dar outra tonalidade à monocracidade dos PCs. Por este motivo quando a Internet desembarcou no Brasil em 1995 não havia uma preocupação gritante com a qualidade do que era publicado na WEB, na realidade a implementação da WEB 2.0 onde a multimídia pode ser uma aliada mais ativa dos desenvolvedores é que possibilitou o crescimento e apelo visual diferenciado.

A cor é um elemento presente e essencial em todos os veículos, com exceção do rádio, mas mesmo assim está no imaginário do ouvinte ao "pensar" a notícia, ao ouvi-la pelo seu aparelho. Ela é responsável por sensações que viabilizam ou impedem o acesso 
de alguns internautas, pois a sua força pode estar relacionada com alguma questão emocional evocada por sua visualização como afirma Modesto Farina em sua obra "Psicodinâmica das Cores em Comunicação":

As cores constituem estímulos psicológicos para a sensibilidade humana, influindo no indivíduo, para gostar ou não de algo, para negar ou afirmar, para se abster ou agir. Muitas preferências sobre as cores se baseiam em associações ou experiências agradáveis tidas no passado e, portanto, torna-se difícil mudar as preferências sobre as mesmas. (FARINA, 2013, p.96)

A sua força também é mais presente nas telas dos computadores do que nos materiais impressos, pois neste segundo são utilizadas apenas quatro tonalidades que não têm muitas nuances diferenciadas: são as chamadas CMYK, onde o C é o Ciano (uma mistura das luzes azul e verde), M é Magenta (um tom de vermelho), Y é o Yellow (amarelo) e o K representa a palavra Key (em inglês, chave) que é a cor preta que faz a ligação entre as demais cores para formar suas variações. É um tipo de sistema de cores que só pode ser utilizado em materiais impressos. Já para a Internet (telas dos computadores e mídias móveis) utilizamos o sistema RGB (Red: vermelho, Green: verde e Blue: azul) com estes sistemas podemos chegar até 16 milhões de combinações e tonalidades de cores possíveis o que abriu um novo mundo para as imagens (estáticas e animadas) e a criação de ambientes virtuais onde o internauta possa navegar com uma sensação maior de realismo.

\section{As citações como ferramenta de estilo}

Ainda na questão da legibilidade alguns itens comuns no jornalismo tradicional precisam ser adaptados para a mídia online, como por exemplo, o uso de aspas, pois uma grande dúvida entre os profissionais de imprensa e estudantes é a correta utilização de aspas em citações. O que devemos ter em mente é que tudo vai depender do foco desejado na hora da publicação da matéria ou do tipo de assunto. É importante manter uma leitura limpa, clara e ágil. Foram criadas, pelo pesquisador, algumas regras básicas que podem ajudar na concepção do conteúdo e inserção de opiniões de especialistas nos textos digitais, estes itens foram retirados do manual básico de redação do site Expressão 
Online (EOL) - www.expressaoonline.com.br - e foram criadas ao longo das aulas e postagens práticas pelos alunos de Projeto Experimental Online da USJT:

- Não serão adotadas aspas no primeiro parágrafo de um texto, devemos focar e trabalhar o LEAD (primeiras e mais importantes informações de um texto jornalístico) - a utilização de aspas logo no início do texto tirará todo foco da informação básica e importante para a compreensão do texto como um todo o que ocasionará a publicação de uma opinião unilateral de um entrevistado.

- As aspas devem iniciar o parágrafo, ou após um ponto, exemplo: "Somos filhos de uma nação", disse João da Silva,antropólogo. Ou: No Brasil as desigualdades são enormes. "Em nosso país os pobres são marginalizados", afirma João da Silva, antropólogo, desta forma promoveremos uma leitura sem quebras, ou seja, o leitor não interrompe sua linha de raciocínio e mantém a continuidade da ideia.

- Sempre identifique o seu especialista entrevistado, com a ligação de: afirma, diz, confirma, entre outros para apontar uma posição, assim damos maior credibilidade ao assunto tratado e a pessoa que forneceu as informações é citada adequadamente dentro de sua área de atuação. Nunca utilize duas aspas (citações) no mesmo parágrafo, caso contrário haverá o risco de misturar informações e confundir o leitor sem falar no fato de que trabalhamos parágrafos mais curtos no meio online e com a utilização de duas citações deixamos de publicar a informação direta para valorizar apenas a opinião.

- Pode-se fechar um texto com aspas no último parágrafo de sua matéria, mas tome o cuidado de ser uma afirmação importante e que seja algo essencial para informar. Não se pode encerrar um texto de maneira abrupta ou sem sentido. Caso exista uma citação que faça esse tipo de fechamento utilize para ilustrar os pontos defendidos na matéria publicada.

- O parágrafo todo poderá ser de uma aspa (citação), desde que seja necessário ao texto, é um grande risco, mas se o parágrafo anterior ou posterior contiver mais dados que embasem as aspas não haverá problemas. 
- Nunca faça uma aspa tripla, ou seja, ao tentar destacar uma palavra dentro da citação uma aspa simples é aberta e depois fechada com aspa normal, exemplo: “O maior problema da miséria é a falta de uma ajuda mais 'dura', tente manter o foco antes do fechamento das aspas para evitar este conflito, não podemos esquecer que a leitura também engloba o design e o visual da matéria e qualquer tipo de conflito afeta a legibilidade.

- Tome o cuidado de não fazer uma sucessão de aspas em todos os parágrafos, caso contrário seu texto será um monólogo do entrevistado e não uma matéria jornalística, um erro comum, mas que deve ser evitado a todo custo.

- Ao entrevistarmos um especialista, suas falas podem ser perfeitas para o texto e a tentação de publicar o maior número possível de argumentos é grande, mas deve ser feita a seleção de pontos mais importantes e interessantes para que o conteúdo não vire uma entrevista unilateral com a pessoa que seria apenas a base para confirmar ou não os pontos defendidos no texto.

\section{Os veículos de comunicação e o texto digital}

Como em outras mídias, não há uma padronização textual, ou seja, cada veículo segue seu próprio manual de redação e estilo que representa o conjunto de ideias e conceitos que devem ser apresentados em uma matéria jornalística. Claro que a obediência das regras gramaticais e de concordância é um ponto em comum para a produção dos materiais jornalísticos. Esta falta de padrão é notada em maior escala na Internet, pois quando os jornais impressos perceberam a importância em manter uma versão digital de seus periódicos na grande rede de computadores, não houve a preocupação em propiciar ao leitor um novo estilo de texto, nenhuma formatação especial, apenas a migração do texto do papel para a tela do computador. Isto gerou graves problemas de leitura, pois a leitura no impresso é feita de maneira linear, ou seja, sem a interação com outros elementos como vídeos e um maior número de imagens e segue um único sentido de cima para baixo. Já no online a sequência de leitura segue o mesmo padrão da leitura tradicional, pois é o que o leitor está habituado como diz Pinho sobre o elemento do design sequência que:

Revista Pauta Geral-Estudos em J omalismo, Ponta Grossa, vol.3, n.1 p. 41-56, J an/J un, 2016. 
Portanto, a sequência diz respeito à condução do leitor pelos elementos da página. Como os olhos movimentam-se habitualmente da esquerda para a direita e de cima para baixo, o designer pode dispor os elementos para que eles comecem se fixando no ângulo superior esquerdo e desçam progressivamente em diagonal da esquerda para a direita e de cima para baixo. No movimento em "Z", a maneira mais comum de controlar e conduzir os olhos, os elementos são colocados no caminho do que pode ser considerado o movimento normal da vista. (PINHO, 2003, p.160)

Desta forma o leitor ou interleitor - que é o leitor dos conteúdos produzidos para a Internet e citado pelo pesquisador em suas palestras - tem o poder de "zapear" dentro dos sites que mais the agradar sem ficar preso às amarras da ditadura do papel que ao terminar uma folha de notícias não há mais o que fazer a não ser aguardar o dia seguinte, enquanto que na Internet as informações podem ser atualizadas a cada instante.

(...) o texto foge da linearidade convencional imposta pelo impresso e seduz o leitor com a possibilidade de escolha na forma de ler o conteúdo, ou seja, o texto digital deve informar no início os dados principais da notícia de forma a conquistar o internauta, ou como vou denominá-lo para facilitar e adequar à nova mídia: o interleitor, o que busca a informação digital. Essa informação inicial transmite os dados básicos de uma notícia: Quem, Como, Onde e assim sucessivamente fornecendo condições de uma visão ampla do fato. Nos veículos impressos o lead inicia o texto e na sequência o mesmo é trabalhado com informações adicionais lineares em colunas e parágrafos. No meio digital o lead tem funcionado como uma espécie de "vitrine" da matéria, ou seja, o interleitor lê o conteúdo inicial e se gostar pode se aprofundar no assunto através de um hiperlink disponível no texto. (FURLANETTO, 2014, p.2)

No online temos a possibilidade de agregar estilos de vários tipos de mídia: o texto do impresso, a imagem e som da televisão e a agilidade do rádio que é relacionado ao conceito de multimidialidade que estabelece entre o indivíduo e o conteúdo uma interação que permitirá a junção de mídias distintas ${ }^{3}$. Nilson Lage cita "a existência de uma integração entre o texto e a organização das páginas, o estilo gráfico e os infográficos estáticos ou dinâmicos":

Não se trata, aqui, de escrever como no jornal, mas de projetar o texto em dois ou três passos: (a) o título ou flash lead; (b) na mesma página ou em hiperlink um bloco que corresponde ao lead 
impresso, mas lembra, pela linguagem, a nota lida ao vivo na televisão; e, facultativamente, (c) o corpo da matéria com a opção de imprimir. É possível, mas ainda raro, que o portal ofereça a matéria prima de que se extraiu a informação: o inteiro teor da entrevista telefônica; link para a íntegra de documentos legais etc. (LAGE, 2012, p.175)

A produção digital de conteúdo significa, segundo o autor Bruno Rodrigues (2000, p.5), "aliar texto, design e tecnologia, e tratá-los como um componente único - a informação", ou seja, não basta termos um conteúdo bem produzido, devemos ter como complementação os novos recursos tecnológicos e uma diagramação atraente para que o fato transformado em informação de valor possa ser devidamente assimilado pelo leitor.

Algumas regras podem ser adotadas para melhorar a produção de textos na Internet, mas é sempre importante lembrar que estamos lidando com diversos tipos de público e o conteúdo pode ser considerado, em muitos casos, como um produto a ser apresentado aos clientes (usuários), claro sem perder o objetivo principal de todo texto jornalístico: informar e apurar o seu fato. Neste ponto a produção digital conquista a cada dia um espaço maior por permitir agregar maior valor aos textos e possibilitar uma maior interação entre o veículo e seu leitor - ou agora também conhecido como usuário - que pode usufruir dos benefícios que a tecnologia aliada à produção textual fornece.

Ter em mente o tipo de linguagem ou abordagem que o cliente quer dar ao produto. O conteúdo textual está diretamente ligado à preocupação com o consumidor. É nesse momento que se estabelecerão os tipos de expressões que podem ser usadas ou adaptadas. Se o público é crítico e politizado, pode-se conquistá-lo com pequenas ironias no texto. Se o público é ligado à música, é claro que poderão ser usadas, desde que moderadamente, expressões que dizem respeito ao estilo definido (por exemplo, no lançamento de um disco num site). Se o público valoriza a informação e a qualidade de uma empresa em detrimento das qualidades das concorrentes, é preciso pôr tudo isso num texto claro e direto, de forma séria e concisa, pois, nesse caso, estamos lidando com empresários. (MOURA, 2002, p.77)

Os nichos de leitores na Internet possibilitam a criação de conteúdos diferenciados, seguindo os gostos e tendências deste público específico. Este ponto reflete a questão da usabilidade que um sistema tem em agradar o seu usuário. Segundo o autor Eduardo Mercovich, "definimos usabilidade de um sistema ou ferramenta como uma medida de sua utilidade, facilidade de uso, facilidade de aprendizagem e apreciação 
para uma tarefa, um usuário e um determinado contexto". Desta forma temos a condução do internauta pela interface desenvolvida e aplicada ao gosto de seu público.

O mesmo ocorre em maior grau no Facebook, onde as pessoas procuram outras que tenham os mesmos gostos e interesses - neste caso os veículos buscam diversificar criando páginas onde relacionam seus leitores com os interesses procurados. Só para citar uma rede social que foi desativada em 2014, no ORKUT, eram trabalhadas comunidades ao invés de páginas. Os interessados em determinados assuntos específicos criavam locais em que suas ideias e expressões de vida poderiam ser exploradas por pessoas com os mesmos objetivos como podemos ver na figura abaixo.

Figura 3: Imagem ilustrativa da rede social Orkut

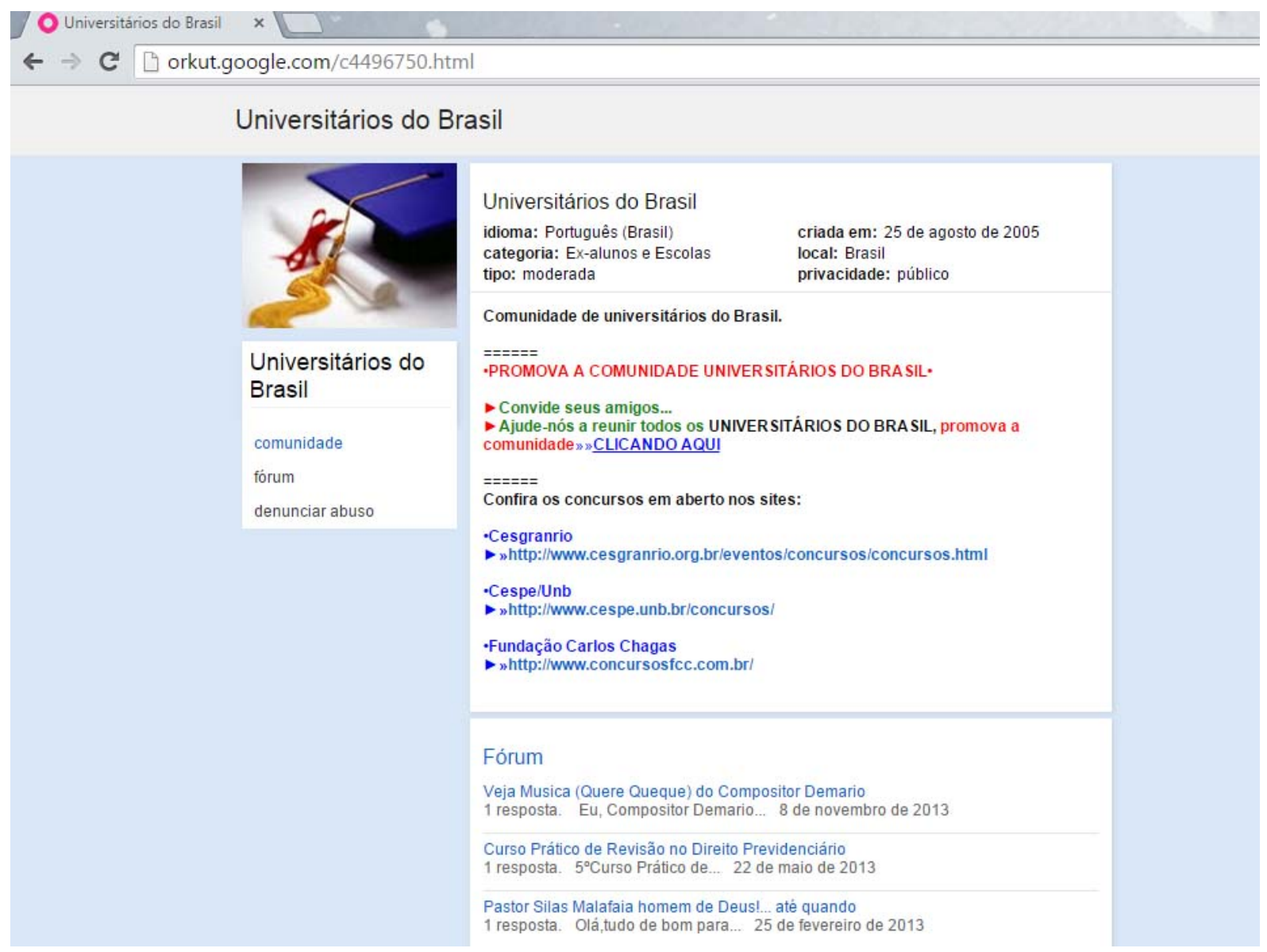

Fonte: $\underline{\text { http://orkut.google.com/c4496750.html }}$

Revista Pauta Geral-Estudos em J omalismo, Ponta Grossa, vol.3, n.1 p. 41-56, J an/J un, 2016. 


\section{As diferenças entre mídias impressas e digitais}

Para termos uma ideia clara das diferenças entre os veículos impressos e os digitais é necessária uma breve explicação sobre o tipo de leitura encontrada em cada um. No primeiro temos uma forma linear de texto e padronização de tamanho para a folha do jornal. O formato "Standard" é adotado pelos maiores jornais do mundo como o ideal para uma leitura visualmente agradável. Na Internet a única limitação é a tela do computador, mas que não impossibilita uma leitura ágil. O recurso do hiperlink permite ao usuário visualizar outro texto ou parte do mesmo texto, a partir de palavras ou caracteres destacados na apresentação visual do hipertexto (textos nos quais existem palavras ou símbolos que estão ligados a outros textos).

De forma bem simplificada, poder-se-ia dizer que o termo hipertexto designa uma escritura não-sequencial e não-linear, que se ramifica de modo a permitir ao leitor virtual o acesso praticamente ilimitado a outros textos, na medida em que procede a escolhas locais e sucessivas em tempo real. $(\mathrm{KOCH}, 2007, \mathrm{p} .25)$

Com a utilização desses recursos o texto foge da linearidade do convencional imposta pelo impresso e seduz o leitor com a possibilidade de escolha na forma de ler o conteúdo. Além disso, há elementos que caracterizam a melhoria da leitura na Internet e representam a navegabilidade, interação e compreensão dos conteúdos existentes. Definamos a navegabilidade como a maneira que o internauta se move dentro de um projeto WEB (site, blog, rede social) a interação fornece as ferramentas necessárias para que as pessoas possam trocar ideias e "conversar" com o conteúdo, já a compreensão dependerá das referências dos usuários e de suas relações com os temas abordados neste ponto é importante ressaltar que há um novo elemento que gera o tipo de leitura que é a participação na geração do próprio conteúdo, pois a leitura nos meios digitais criou, ou melhor, possibilitou ao leitor a posição colaborador mais ativo da formação da informação.

O principal ponto com o qual os veículos de comunicação tradicionais lidam é o fato de que as ferramentas da web 2.0 permitem que qualquer cidadão, em qualquer parte do mundo - desde que tenha acesso à rede -, publique

Revista Pauta Geral-Estudos em J omalismo, Ponta Grossa, vol.3, n.1 p. 41-56, J an/J un, 2016. 
fatos, opiniões, análises, sem se preocupar com questões como custos de impressão ou distribuição. O resultado disso? Se antes era função exclusiva da mídia e de seus profissionais decidir quais temas seriam publicados e quais não - com base em critérios como relevância e, por que não?, espaço ou tempo disponível -, agora os assuntos são publicados em todas as partes e a todo momento. Se antes se filtrava para publicar, hoje se publica para depois filtrar. (KÜNSCH;MARTINO, 2010, p.132 e 133)

Nos dias atuais vivemos o problema do acúmulo de tarefas e a falta de condições para selecionar um momento do dia e aprofundar uma leitura de jornal. Esse "tempo" de análise textual está comprovadamente reduzido e por este motivo os sites que fornecem conteúdo para Internet buscam um texto objetivo, como deixa claro Moura (2002, p.56) "Frases curtas e pontuação são essenciais na rede. Controlar o ritmo da frase e preferir sempre períodos curtos fazem a diferença para quem lê numa tela de computador."

Mas há uma convergência de outras mídias que agregam maior valor a notícia, quando o conteúdo é publicado e tem a opção de exibir um vídeo, ou se colocar mais imagens do fato para ilustrar como ocorreu em uma sequência e não apenas aquela foto escolhida no meio de tantas outras.

No capítulo anterior foi citado que o tipo de leitor mais comum na Internet é o "scanner", que faz uma leitura por varrimento visual para buscar o que for de seu interesse. Mas existem ainda mais quatro tipos de leituras que pode ser encontradas e são citadas por Pinho (2003, p.192), que são as leituras superficial, por varrimento, intensiva e extensiva:

Leitura superficial: Os leitores movem rapidamente seus olhos sobre a tela do computador para verificar se o material é relevante para suas necessidades. Similar ao que acontece com o texto impresso, quando um leitor corre primeiro os seus olhos no documento para retirar dele o que é essencial. Leitura por varrimento: Se o texto da WEB preenche suas necessidades, os leitores vão rapidamente focalizar partes específicas de informação e podem depois fazer a rolagem da tela. Leitura intensiva: Como no documento impresso, os leitores param, por haverem decidido que o texto é relevante, e leem uma pequena quantidade de conteúdo para obter uma informação mais aprofundada. Leitura extensiva: A grande maioria dos usuários não gosta da leitura extensiva online e preferem imprimir o texto para ler, por razões como o fato de a leitura na tela ser mais lenta e a baixa resolução do monitor provocar fadiga visual. Alguns usuários ainda têm restrições de tempo por causa do custo da ligação telefônica com o provedor ou por estar acessando a internet em computador de uma biblioteca 
pública. (HEMMERICH; HARRISON, 2002 apud PINHO, 2003, p.192)

Temos que apenas desconsiderar parcialmente as afirmações do tipo de leitura extensiva, pois atualmente não temos mais o problema de acesso por conexão discada e falta de equipamentos (computadores), mas este ponto é interessante ser discutido brevemente para que possamos ter uma ideia de como a leitura na internet avançou nos últimos anos, mas ainda há pessoas que preferem ler em papel a fazê-lo na tela dos computadores.

Quando não havia conexão por fibra ótica, apenas para citar um tipo, o usuário era obrigado a se conectar por meio de um modem e linha telefônica, a alta tarifa das ligações, a lentidão da conexão e o alto custo dos equipamentos deixavam grande parte da população fora do acesso a WEB. Com a popularização dos hardwares e avanços tecnológicos constantes, atualmente é quase impossível encontrar alguma pessoa sem nenhum tipo de acesso à internet, seja por smartphone, tablete o computadores (desktops ou notebooks) o que contribuiu para a melhoria da comunicação mediada por computadores (CMC) e a procura por informações aumentou com o acesso aos meios de comunicação disponíveis na grande rede.

Então um grande facilitador da leitura nos meios digitais é a tecnologia aliada aos recursos de acessibilidade existentes, mas um grande limitador ainda é a tela onde são exibidas as notícias, sejam monitores maiores ou menores. O problema é de que maneira serão formatadas as informações para a inserção e absorção do público.

O internauta busca agilidade e objetividade, ou seja, textos extensos afastam um possível leitor da internet. O que deve ser trabalhado é a fragmentação por meio dos links, como citado anteriormente, a publicação de materiais longos e cansativos apenas afastará os leitores do site ou portal, neste caso as redes sociais não trabalham com esse tipo de conteúdo mais longo, os usuários precisam ter a informação de maneira mais curta e direta, dada a necessidade constante de tempo para outros afazeres e procurar transmitir a informação de forma clara é a melhor solução.

\section{Considerações Finais}

Podemos considerar que no atual cenário de criação e publicação de conteúdo faz-se necessária uma ação mais direta e objetiva por parte dos veículos de comunicação Revista Pauta Geral-Estudos em J omalismo, Ponta Grossa, vol.3, n.1 p. 41-56, J an/J un, 2016. 
em promover o desenvolvimento de ferramentas e critérios que possibilitem uma melhor e maior legibilidade de seus produtos textuais na Internet.

Mas não devemos ficar restritos ao âmbito de websites de grandes portais de notícias e/ou blogs, o espectro de publicações é muito mais amplo e atinge diferentes níveis e tipos de leitores: são os já citados sites, blogs e mais mídias sociais digitais (Facebook e Twitter) Youtube (canal de veiculação de vídeos e/ou áudios), smartphones, tablets, smartwatch entre outros. A produção de textos para estas mídias deverá ser processada sempre de acordo com o perfil do usuário interessado, do tamanho de tela e tempo de leitura, pois nos dias atuais as pessoas estão cada vez mais apressadas e seus compromissos ultrapassam as linhas dos escritórios de empresas e acompanham os leitores em todos os momentos. Por este motivo a fragmentação proporcionada pela criação de hipertextos com as ligações fornecidas pelos hiperlinks possibilita a transição necessária entre texto, vídeo e imagem gerando a convergência necessária entre o mundo digital e a acessibilidade humana.

As mídias de imprensa ainda buscam uma identidade própria e estão presas na necessidade de informar segundo a segundo correndo o risco de publicar um conteúdo com erros de informações ou gramaticais, que diferentemente do impresso pode ser corrigido com um simples clique, mas neste ponto perde-se a credibilidade, pois um veículo que prefere publicar sem revisar corre o grande risco de perder leitores que a cada dia são mais exigentes e conectados. Uma postagem publicada na grande rede de computadores por poucos segundos e retirada imediatamente, já está "gravada" em algum servidor da WEB ou foi lida e copiada por algum leitor, então devem ser as maiores preocupações dos jornais, revistas e promotores textuais digitais, a apuração e correção dos conteúdos antes de sua publicação na Internet.

\section{REFERÊNCIAS}

\section{BITENCOURT, M. C. A. Interatividade, hipertextualidade e multimidialidade no}

processo de convergência da cobertura de protestos pelo coletivo Mídia Ninja.

Revista ALCEU, Rio de Janeiro, v. 14 - n.28 - p. 188 a 201 - jan./jun. 2014.

FARINA, M.; PEREZ, C.; BASTOS, D. Psicodinâmica das cores em comunicação. São

Paulo: Edgar Blucher., 2013.

Revista Pauta Geral-Estudos em J omalismo, Ponta Grossa, vol.3, n.1 p. 41-56, J a n/J un, 2016. 
FURLANETTO, C. A Legibilidade textual na produção de conteúdo jornalístico na Internet. $10^{\circ}$ Interprogramas de mestrado Faculdade Cásper Líbero. São Paulo, SP - 7 e 8 de novembro de 2014.

$\mathrm{KOCH}$, I. G. V.: Hypertext and the construction of sense. Alfa, São Paulo, v.51, n.1, p.23-38, 2007 - Disponível em http://seer.fclar.unesp.br/alfa/article/viewFile/1425/1126

KÜNSCH, D. A.; MARTINO, L. M. S. Comunicação, jornalismo e compreensão. São Paulo: Pleiade, 2010.

LAGE, N. Estrutura da notícia. 6. ed. rev. e atual. São Paulo: Atica, 2012.

MOURA, L. de S. Como escrever na rede: manual de conteúdo e redação para Internet. Rio de Janeiro:Record,2002.

PINHO,J.B. Jornalismo na Internet: planejamento e produção da informação on-line. São Paulo:Summus,2003.

WARDE, M. Jornalismo online. São Paulo: Roca, 2006.

WILLIAMS, R.; TOLLETT, J. Web design para não-designers: um guia objetivo para você criar, projetar e publicar o seu site na web. Rio de Janeiro: Ciência Moderna, 2001.

Recebido em 23/11/2015

Publicado em 27/04/2016

Revista Pauta Geral-Estudos em J omalismo, Ponta Grossa, vol.3, n.1 p. 41-56, J an/J un, 2016. 